\title{
COMMENTARY
}

\section{What do we really know about sponge-microbial symbioses?}

\author{
Nicole S Webster and Linda L Blackall
}

The ISME Journal (2009) 3, 1-3; doi:10.1038/ismej.2008.102; published online 30 October 2008

The marine biosphere is well-endowed with functionally critical symbioses. Coral symbiosis research has principally been driven by the need to understand the fundamental importance of the photosynthesizing zooxanthellate symbionts to the survival of the coral animal host. In contrast, sponge symbiosis research has largely been motivated by the discovery of bioactive molecules (Taylor et al., 2007b). Thus, the microbial symbionts from sponges have been studied chiefly in relation to their biodiversity and biogeography. Two recent articles on microbial symbiosis in marine sponges (Taylor et al., 2007a; Vogel, 2008) emphasize the significance of the high density and diversity of resident microbes to sponge function and the utility of sponge microbial diversity to pharmacologists and biotechnologists. Focal points raised by these articles for future research include: 'the evolution of symbiont diversity, microbial metabolism, hostmicrobe interactions and potential biotechnological implications'. As these are very important research directions, due consideration should also be afforded to additional key research areas, including (i) the significance of microbial associations to sponge health (by enhancing our understanding of the specific functions of sponge symbionts and investigation of other 'symbiotic' processes such as disease), (ii) the consistency and stability of the symbioses across wider environmental gradients and (iii) the sensitivity of the symbioses in the face of global change. Here we broaden the scope of the recent commentaries on sponge symbiosis to include these critical environmental issues.

To date, there is little direct evidence confirming the contribution of symbiotic microbes to sponge well-being or survival. An exception involves the cyanobacteria, in which earlier studies (comprehensively reviewed in Taylor et al., 2007b) have shown translocation of photosynthate from cyanobacteria to the host sponge (Wilkinson, 1979) and a decline in sponge health with a loss of cyanobacteria (Thacker, 2005). However, in general, the presence of microbes with certain metabolic phenotypes only provides circumstantial evidence that they are important for sponge health. Examples include ammonium-oxidizing archaea (Steger et al., 2008), the nitrite-oxidizing phylum Nitrospira (Hentschel et al., 2002), sulphate-reducing bacteria (Hoffmann et al., 2005), anaerobic phototrophs (Imhoff and Trüper, 1976) and vertical transfer of some microbial populations from parent sponge to larval offspring (for example, Steger et al., 2008 and references therein). However, additional research is required to reveal the cellular and molecular interactions (the critical functional aspects) of sponge-microbial symbiotic relationships. The interaction between the host and the symbiont has been identified earlier as a focal point for future research (Taylor et al., 2007a); however, to date, research into sponge microbiology has not elucidated the roles bacteria play in sponge biology and ecology. As the concept of 'who eats what, where and when?' is considered a Holy Grail in studies of microbial ecology (Neufeld et al., 2007), an appreciation of symbiotic function requires a grasp of the communication between the host and its symbionts: understanding the language spoken between the host and symbiont should reveal how the symbiosis occurs and what compels the association to persist.

In recent years, there have been numerous reports that sponge disease (Figure 1a) is a global phenomenon that may adversely affect the health and ecology of reef systems (reviewed in Webster, 2007). The most significant challenges identified for the management of sponge disease are the lack of fundamental information on the causative agents, identification of reservoirs/vectors of disease and the role of environmental stressors (Figure 1b). Future sponge microbiology research should, therefore, also include a focus on developing suitable assays and indicators for assessing sponge health, determining the prevalence and aetiological agents of sponge disease, and evaluating innate sponge immunity and pathogen virulence mechanisms. These types of studies would also advance our understanding of the mechanisms by which sponges can make critical distinctions between symbionts, food and pathogens.

Despite the stability of many sponge-bacterial associations and strong evidence for a uniform microbial community in multiple sponge species 

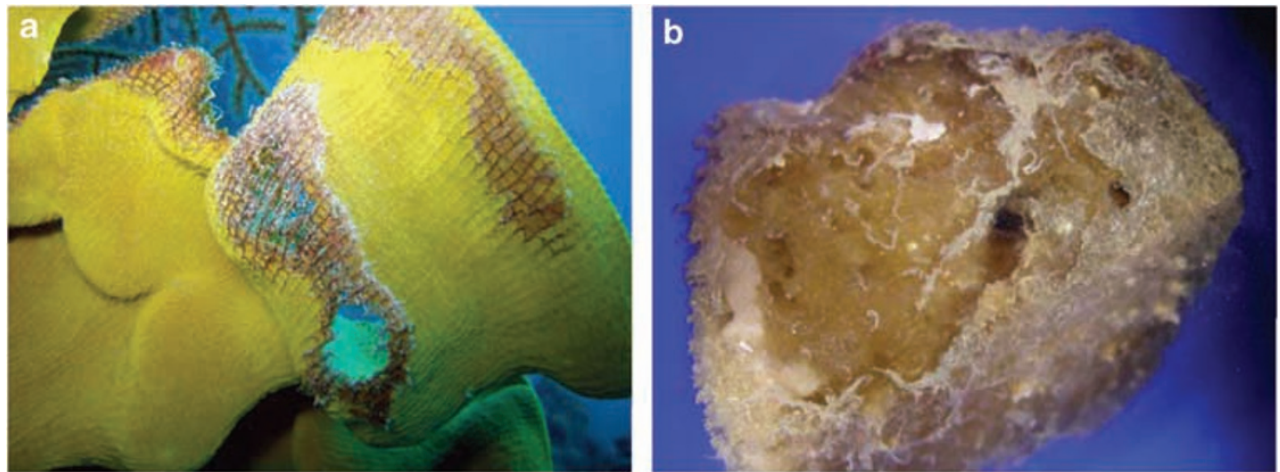

Figure 1 (a) A diseased specimen of the GBR sponge Ianthella basta showing tissue lesions, (b) the GBR sponge Rhopaloeides odorabile after experimental exposure to elevated seawater temperature $\left(33^{\circ} \mathrm{C}\right.$ for $\left.24 \mathrm{~h}\right)$ showing large areas of necrosis and skeletal fibres protruding from the pinacoderm. GBR, great barrier reef.
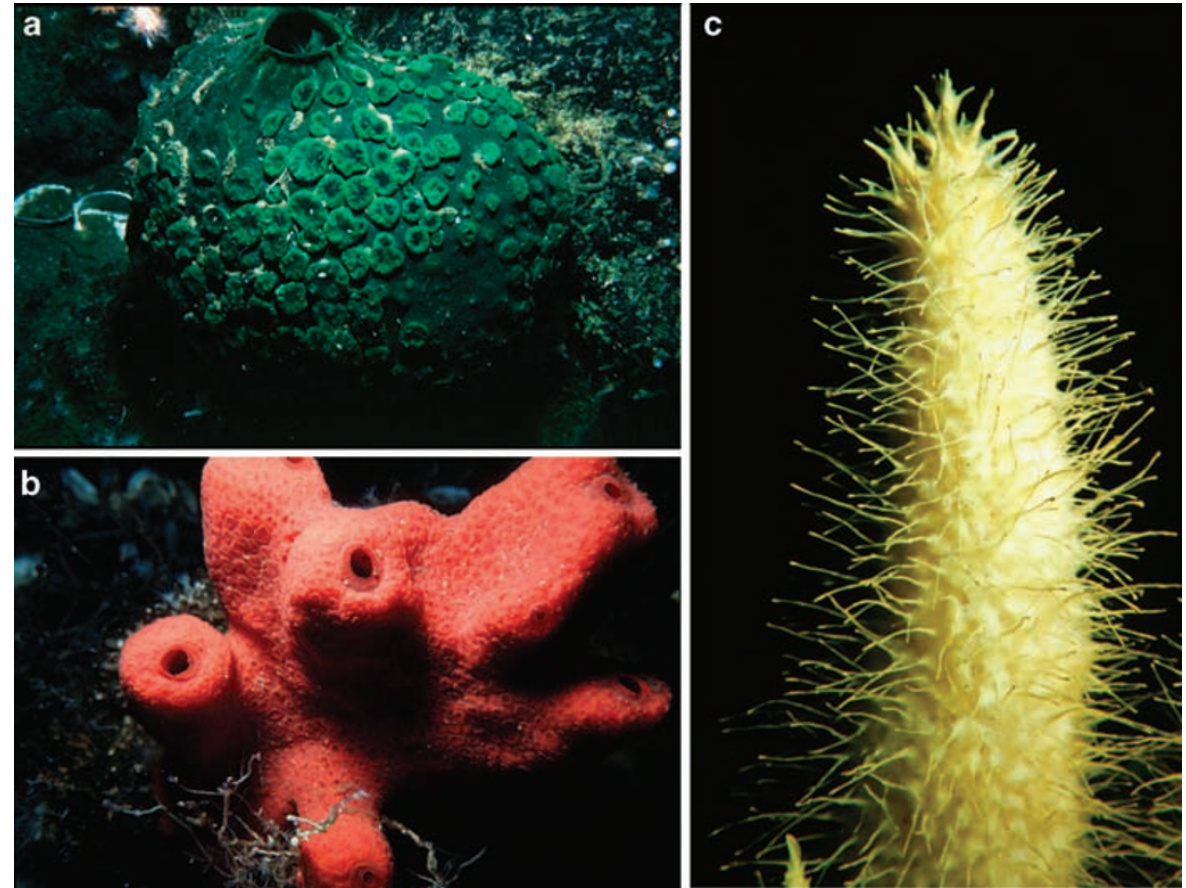

Figure 2 The Antarctic sponges (a) Latrunculia apicalis, (b) Kirkpatrickia varialosa and (c) Isodictya setifera.

from different oceans (Hentschel et al., 2002; Taylor et al., 2007b), few studies have examined the stability of these associations over wider environmental scales. For example, there is only one report of Antarctic sponge symbiosis (Figure 2), and that study revealed conserved bacterial communities with higher similarity to Antarctic sea-ice and Antarctic sediment microbes than to known sponge 'symbionts' (Webster et al., 2004). Despite the widespread biogeographic stability in tropical and temperate sponge-microbe associations, correlations of stability with environmental gradients such as temperature, light, nutrients, and so on, lack research attention and would greatly enhance our understanding of the importance of specific symbiotic associations in sponge health.

In today's climate of rapidly accelerating environmental change, a mechanistic understanding of the sensitivity of sponge symbioses to environmental stress is urgently required. This has been well recognized and studied in other systems (for example, coral-algal symbioses), but has largely been ignored in the field of sponge-microbe symbiosis. Sponges are sessile marine invertebrates that filter great volumes of seawater (a $1 \mathrm{~kg}$ sponge can filter up to $24000 \mathrm{l}$ of seawater per day) (Vogel, 1977), and therefore have the potential to be directly and severely impacted by adverse environmental conditions. Considering the predominance, complexity and specificity of microbes within sponges, it seems likely that shifts in microbial communities due to climate change/environmental stress will affect sponge health, growth rates or their capacity for defence from predation, fouling and disease. However, as analysis of microbial community shifts in response to temperature (Lemoine et al., 2007; 
Webster et al., 2008) and heavy metals (Webster et al., 2001; Selvin et al., 2007) have correlated with declines in sponge health, no studies have examined the mechanisms linking symbiotic community structure and sponge health. Furthermore, there is little comprehension of the adaptive capacity of sponge symbioses and how the resilience of the relationships will be affected by genetic turnover, functional redundancy, expression of stress-regulated genes and lateral gene transfer.

Our knowledge of sponge-bacterial symbioses remains rudimentary. Two recent commentaries (Taylor et al., 2007a; Vogel, 2008) and this one have outlined our current comprehension and have identified the most important next steps in understanding these unique animals and their resident symbionts. Cracking the codes of communication between sponge and symbiont remains the key to unlocking the black box of symbiosis function and will greatly benefit all areas of research from biodiversity and biotechnology to understanding the effects of human impacts and climate change.

\section{Acknowledgements}

We thank Heidi Luter for providing the image shown in Figure 1A.

NS Webster and LL Blackall are at Microbiology and Symbiosis, Australian Institute of Marine Science, PMB 3 Townsville Mail Centre, Townsville, Australia. E-mail: n.webster@aims.gov.au

\section{References}

Hentschel U, Hopke J, Horn M, Friedrich AB, Wagner M, Hacker J et al. (2002). Molecular evidence for a uniform microbial community in sponges from different oceans. Appl Environ Microbiol 68: 4431-4440.

Hoffmann F, Larsen O, Thiel V, Rapp H, Pape T, Michaelis W et al. (2005). An Anaerobic World in Sponges. Geomicrobiol J 22: 1-10.

Imhoff JF, Trüper HG. (1976). Marine sponges as habitats of anaerobic phototrophic bacteria. Microb Ecol 3: 1-9.
Lemoine N, Buell N, Hill A, Hill M. (2007). Assessing the utility of sponge microbial symbiont communities as models to study global climate change: a case study with Halichondria bowerbanki. In: MR Custódio, G Lôbo-Hajdu, E Hajdu, G Muricy (eds). Porifera Research: Biodiversity, Innovation, and Sustainability. Série Livros 28, Museu Nacional, Rio de Janeiro, pp 419-425.

Neufeld JD, Wagner M, Murrell JC. (2007). Who eats what, where and when? Isotope-labelling experiments are coming of age. ISME J 1: 103-110.

Selvin J, Shanmugha Priya S, Seghal Kiran G, Thangavelu T, Sapna Bai N. (2007). Sponge-associated marine bacteria as indicators of heavy metal pollution. Microbiol Res (doi:10.1016/j.micres.2007.05.005).

Steger D, Ettinger-Epstein P, Whalan S, Hentschel U, de Nys R, Wagner M et al. (2008). Diversity and mode of transmission of ammonia-oxidizing archaea in marine sponges. Environ Microbiol 10: 1087-1094.

Taylor MW, Hill RT, Piel J, Thacker RW, Hentschel U. (2007a). Soaking it up: the complex lives of marine sponges and their microbial associates. ISME $J$ 1: 187-190.

Taylor MW, Radax R, Steger D, Wagner M. (2007b). Sponge-associated microorganisms: evolution, ecology, and biotechnological potential. Microbiol Mol Biol Rev 71: 295-347.

Thacker RW. (2005). Impacts of shading on spongecyanobacteria symbioses: a comparison between host-specific and generalist associations. Integr Comp Biol 45: 369-376.

Vogel G. (2008). The inner lives of sponges. Science NY 320: 1028-1030.

Vogel S. (1977). Current-induced flow through living sponges in nature. Proc Natl Acad Sci USA 74: 2069-2071.

Webster NS. (2007). Sponge disease: a global threat? Environ Microbiol 9: 1363-1375.

Webster NS, Cobb RE, Negri AP. (2008). Temperature thresholds for bacterial symbiosis with a sponge. ISME J 2: 830-842.

Webster NS, Negri AP, Munro MM, Battershill CN. (2004). Diverse microbial communities inhabit Antarctic sponges. Environ Microbiol 6: 288-300.

Webster NS, Webb RI, Ridd MJ, Hill RT, Negri AP. (2001). The effects of copper on the microbial community of a coral reef sponge. Environ Microbiol 3: 19-31.

Wilkinson CR. (1979). Nutrient translocation from symbiotic cyanobacteria to coral reef sponges. In: C Levi, N Boury-Esnault (eds). Biologie des Spongiaires, pp 373-380, Coli. Int. C.N.R.S., Paris, No. 291. 